\title{
Use of the internet as a source of health information by Spanish adolescents
}

\author{
Jaime Jiménez-Pernett ${ }^{1,3}$, Antontio Olry de Labry-Lima12,2,3, Clara Bermúdez-Tamayo ${ }^{1,3^{*}}$, \\ Jose Francisco García-Gutiérrez ${ }^{1,2,3}$, Maria del Carmen Salcedo-Sánchez ${ }^{2,3}$
}

\begin{abstract}
Background: The Internet is a fundamental part of the daily life of adolescents, they consider it as a safe and confidential source of information on health matters. The aims is to describe the experience of Spanish adolescents searching for health information on the Internet.

Methods: A cross-sectional study of 811 school-age adolescents in Granada was carried out. An adapted and piloted questionnaire was used which was controlled by trained personnel. Sociodemographic and health variables were included together with those concerning the conditions governing access to and use of information and communication technologies (ICT).
\end{abstract}

Results: 811 adolescents were surveyed (99.38\% response rate), mean age was 17 years old. Of these, $88 \%$ used the Internet; $57.5 \%$ used it on a daily or weekly basis and $38.7 \%$ used it occasionally. Nearly half the sample group (55.7\%) stated that they used the Internet to search for health-related information. The main problems reported in the search for e-health were the ignorance of good web pages (54.8\%) and the lack of confidence or search skills (23.2\%).

Conclusions: In conclusion, it seems plausible to claim that websites designed and managed by health services should have a predominant position among interventions specifically addressed to young people.

\section{Background}

The Internet is increasingly becoming part of our lives, its use being centred on the younger age-group (90.3\% of citizens between 15 and 24 and $78.3 \%$ between 25 and 34 years of age are Internet users) [1].

The Internet is a fundamental part of the daily life of adolescents; they maintain permanent contact with their friends, form friendships with people who share their interests and hobbies and widen their knowledge $[2,3]$. As a consequence, this phenomenon has turned the Internet into one of the main means of communication between adolescents and is the reason why the younger age-group must be trained in the correct use of the Internet in relation to health information [4]. There are many reasons why the young are prompted to use the Internet, mainly because it is fast and easy and because it provides a great deal of information [5].

\footnotetext{
* Correspondence: clara.bermudez.easp@juntadeandalucia.es

${ }^{1}$ Andalusian School of Public Health, Granada, Spain
}

This is a particularly important aspect owing to the fact that adolescents find it hard to access traditional health services; the Internet also provides them with a confidential and safe source of health information [6]. The environment in which patients consume medical and health information has changed dramatically during the past decade. Rapid diffusion of Internet technology within the public sphere has placed an unprecedented amount of health information within reach of general consumers $[7,8]$. For adolescents, the internet is an integral part of their world, making e-Healthcare not only a reasonable extension of technology but an expectation [9].

In view of all this, this survey aims to describe the experience of adolescents in Andalusia (Spain) searching for health information on the Internet.

\section{Methods}

A cross-sectional survey was carried out on adolescents in their post-compulsory schooling (or $11^{\text {th }}$ and $12^{\text {th }}$ grades in North America) in Andalusian high schools (Spain). 
A calculation of sample size for a prevalence of $50 \%$, with a $5 \%$ accuracy level and $95 \%$ confidence level was carried out, resulting in a total of 700 adolescents; in order to avoid any possible losses, calculation of the sample size was increased by $15 \%$. The sample was selected by equiprobability single-stage cluster sampling. From among 42 secondary education schools providing postcompulsory schooling in Granada (Spain), nine were selected by simple random sampling, subsequently all the pupils attending the selected school were included.

\section{Variables}

1) Sociodemographic and health variables: age, sex, perceived health and the number of visits to the doctor over the previous year. 2) Variables related to the conditions governing the access to and use of information and communication technologies (ICT): Use of the Internet, frequency of use, main use of the Internet (games, travel, shopping, e-Learning, others), who the results are aimed at, opinion of the Internet as a good source of health information and the use of other sources of health information. Three multi-answer questions were formulated in order to obtain the greatest amount of information available to identify Internet access points, sources for health information searches and health subjects searched.

\section{Instruments}

The information was gathered using a structured questionnaire with 22 items. This self-administered questionnaire was adapted and piloted [10]. from a Kaiser Family Foundation study [4]. Their instrument was designed and analyzed by staff of the organization, in consultation with International Communications Research.

\section{Procedure}

Prior to gathering the information, a pilot test was carried out on a sample of 50 adolescents in order to determine the proper functioning of the questionnaire; the data collected was not included in the analyses carried out [10].

First, the research protocol had to be approved by the Research and Ethics Committee of the Progress and Health Foundation of the Andalusian Regional Ministry of Health. Subsequently, contact was made with those in charge of each school and after obtaining approval of the heads and teaching staff of schools, the adolescents were asked to take part in the survey. Informed consent on the part of students was verbally requested.

The questionnaires were controlled by personnel specifically trained for this survey who had good communication skills. In addition, no information was collected that could facilitate the identification of respondents.

\section{Statistical analysis}

A descriptive analysis of the sample group was carried out using the standard frequencies, percentages for qualitative variables and means and deviations for quantitative variables. Eventually, a bivariate analysis was carried out by means of the chi-square test. The analysis was carried out using the statistical programme SPSS 11.5.

\section{Results}

A total of 811 adolescents were studied, $46 \%$ of them were men, 17 years old was the average age of sample (none of the youngsters refused to take part in the survey). An average of 2 visits to the doctor were made over the previous year and $9.3 \%$ reported an average, bad or very bad self-perceived state of health compared with $26.3 \%$ who considered their health to be very good.

As far as the access and use of information and communication technology variables are concerned, $88 \%$ used the Internet, $57.5 \%$ used it on a daily or weekly basis and $38.7 \%$ used it occasionally. Only $7.8 \%$ of the adolescents thought that more information would improve their health.

Nearly half the sample (55.7\%) stated that they used the Internet to search for health information, 19.4\% used it on a daily or weekly basis compared with $25.7 \%$ who used it occasionally during the year/not at all. The main problems reported when searching for e-health was a lack of knowledge of good web pages (54.8\%) and a lack of confidence or search skills (23.2\%). Among those who used the Internet, $82 \%$ stated that it helped them obtain more health information and 54.9\% answered that the Internet helped them obtain better health information (Table 1).

As far as the multi-answer variables are concerned (Table 2), the three most popular sources for obtaining information on health were: family and friends (56.4\%), doctors and nurses (21.9\%) and the Internet (60.4\%). The adolescents reported accessing the Internet mainly from their homes (93.5\%), followed by school centres (28.4\%) and cybercafés (14\%). They mainly used the Internet for leisure pursuits, music and games (90\%), school work (87\%) and chats and forums (79.7\%). And $97.6 \%$ of respondents obtained their health information through a search engine (mainly Google), followed by newspapers $(50.1 \%)$ and out-links in the websites they visited $(45.5 \%)$. Regarding the intended users of the information, $95.6 \%$ of the subjects stated that the information was for personal use. The main reasons for searching health information on the Internet were: easy of use (36.9\%), lots of information (21.7\%) and speed (14.7\%). The main health topics looked up on the Internet were: Self-image, beauty and wellness (56.5\%), fitness and physical activity (53\%) and piercing and tattoos (44.6\%) (Table 3). 
Table 1 Summary of the main variables $(n=811)$.

\begin{tabular}{|c|c|c|}
\hline & & $\mathrm{N}(\%)$ \\
\hline \multirow[t]{2}{*}{ Gender } & Male & $373(46 \%)$ \\
\hline & Female & $438(54,1 \%)$ \\
\hline \multirow[t]{3}{*}{ Perceived health } & Very good & $213(26.3 \%)$ \\
\hline & Good & $521(64.4 \%)$ \\
\hline & Not so good-Bad/very bad & $75(9.3 \%)$ \\
\hline \multirow[t]{2}{*}{ General use of the Internet } & No & $97(12 \%)$ \\
\hline & Yes & $713(88 \%)$ \\
\hline \multirow[t]{3}{*}{ Frequency of use of the Internet } & Daily/A few times a week & $410(57.5 \%)$ \\
\hline & A few times a month & $276(38.7 \%)$ \\
\hline & A few times a year-Never & $27(3.8 \%)$ \\
\hline \multirow[t]{2}{*}{ Do you search for health information on the Internet? } & No & $359(44.3 \%)$ \\
\hline & Yes & $451(55.7 \%)$ \\
\hline \multirow[t]{3}{*}{ Frequency of health information searches on the Internet } & Daily/A few times a week & $88(19.4 \%)$ \\
\hline & A few times a month & $249(54.8 \%)$ \\
\hline & A few times a year - Never & $117(25.7 \%)$ \\
\hline \multirow[t]{3}{*}{ Do you think your QOL would improve if you had more health information? } & No & $63(7.8 \%)$ \\
\hline & Yes & $580(72 \%)$ \\
\hline & Do not know & $162(20.1 \%)$ \\
\hline \multirow[t]{5}{*}{ Problems when looking for health information on the Internet (choose one) } & Do not know good sites & $239(54.8 \%)$ \\
\hline & Lack of search skills & $101(23.2 \%)$ \\
\hline & No Internet at home & $24(5.5 \%)$ \\
\hline & Not interested in the subject & $15(3.4 \%)$ \\
\hline & No confidence/no search/Other & $57(13.1 \%)$ \\
\hline \multirow[t]{9}{*}{ What sources do you use to find health information? (mark all) } & Family and friends & $456(56.4 \%)$ \\
\hline & Magazines, newspapers & $357(44.2 \%)$ \\
\hline & Books/medical encyclopaedias & $179(22.2 \%)$ \\
\hline & Television & $348(43.1 \%)$ \\
\hline & Radio & $29(3.6 \%)$ \\
\hline & Internet & $424(52.5 \%)$ \\
\hline & Doctors, nurses & $488(60.4 \%)$ \\
\hline & Chemists & $177(21.9 \%)$ \\
\hline & None & $54(6.7 \%)$ \\
\hline \multirow[t]{8}{*}{ Why do you search health information on the Internet (choose one) } & Easy & $158(36.9 \%)$ \\
\hline & Lots of information & $93(21.7 \%)$ \\
\hline & Fast information & $63(14.7 \%)$ \\
\hline & Confidential search & $45(10.5 \%)$ \\
\hline & See different opinions & $34(7.9 \%)$ \\
\hline & Free information & $24(5.6 \%)$ \\
\hline & Other & $11(2.6 \%)$ \\
\hline & & Median (DS) \\
\hline Age (in years) & & $17(1.01)$ \\
\hline Visits to the doctor during the previous year & & $2(3.92)$ \\
\hline
\end{tabular}

The bivariant analysis showed that those adolescents who used the Internet on a daily basis were most likely to search for health information (OR: 1.49; IC95\% 2.021.01). Concerning the information sources, those who searched for health information on the Internet demonstrated, with a significant statistical difference, a greater probability of consulting doctors $(60.8 \%$ vs. $51.1 \%)$, magazines $(49.9 \%$ vs. $37.7 \%)$, books ( $27.9 \%$ vs. $14.9 \%)$ and, in contrast, a lesser degree of probability of consulting none (1.6\% vs. $13.6 \%)$.

\section{Discussion}

Moreover, this survey opens a small window through which we can begin to study the opinion that Spanish adolescents hold of the Internet and how they relate to it. Thus it is demonstrated that the young mainly use 
Table 2 Summary of the main variables $(n=811)$.

\begin{tabular}{|c|c|c|}
\hline & & N (\%) \\
\hline \multirow[t]{6}{*}{ Where do you usually access the Internet? (Multiple choice) } & Home & $666(93,5 \%)$ \\
\hline & School & $202(28,4 \%)$ \\
\hline & Cultural or leisure centres & $23(3,2 \%)$ \\
\hline & Cybercafé & $100(14 \%)$ \\
\hline & Mobile phone & $26(3,7 \%)$ \\
\hline & Other places & $52(7,3 \%)$ \\
\hline \multirow[t]{8}{*}{ What do you usually use the Internet for? (Multiple choice) } & Leisure, music, games & $642(90 \%)$ \\
\hline & School work & $620(87 \%)$ \\
\hline & Searching for information & $564(79,1 \%)$ \\
\hline & Shopping & $47(6,6 \%)$ \\
\hline & Courses & $32(4,5 \%)$ \\
\hline & E-mail & $519(72,8 \%)$ \\
\hline & Chat (e.g. messenger), forums & $568(79,7 \%)$ \\
\hline & Others & $49(6,9 \%)$ \\
\hline \multirow[t]{7}{*}{ Why do you look for health information in the internet? (Multiple choice) } & It is free & $24(5,6 \%)$ \\
\hline & It is quick & $63(14,7 \%)$ \\
\hline & It is confidential & $45(10,5 \%)$ \\
\hline & It is easy & $158(36,9 \%)$ \\
\hline & There are a lot of information & $93(21,7 \%)$ \\
\hline & To have different opinions & $34(7,9 \%)$ \\
\hline & Others & $11(2,6 \%)$ \\
\hline \multirow[t]{6}{*}{ ¿How do you look for health information? (Multiple choice) } & Internet searcher & $444(97,6 \%)$ \\
\hline & Family/friends & $167(36,7 \%)$ \\
\hline & Physicians & $39(8,6 \%)$ \\
\hline & News paper, media & $228(50,1 \%)$ \\
\hline & Links of websites & $207(45,5 \%)$ \\
\hline & Others & $17(3,7 \%)$ \\
\hline \multirow[t]{4}{*}{ ¿Whom do you look health information for? (Multiple choice) } & Yourself & $434(95,6 \%)$ \\
\hline & Family & $182(40 \%)$ \\
\hline & Classmates or friends & $142(31,2 \%)$ \\
\hline & Others & $28(6,2 \%)$ \\
\hline
\end{tabular}

Table 3 Twelve main health topics looked up on the Internet $(n=451 *)$.

\begin{tabular}{lr}
\hline \multicolumn{1}{c}{ Health topic } & $\mathbf{N}(\%)$ \\
\hline Body image, beauty and wellness & $255(56,5 \%)$ \\
\hline Fitness and physical activity & $239(53 \%)$ \\
\hline Piercing and tattoos & $201(44,6 \%)$ \\
\hline Contraception & $185(41 \%)$ \\
\hline Nutrition and diet & $184(40,8 \%)$ \\
\hline Sexual behavior & $183(40,6 \%)$ \\
\hline Drugs & $165(36,6 \%)$ \\
\hline Sexually Transmitted Diseases & $147(32,6 \%)$ \\
\hline Skin conditions & $144(31,9 \%)$ \\
\hline Tobacco and alcohol & $119(26,4 \%)$ \\
\hline Eating disorders & $103(22,8 \%)$ \\
\hline Physical development & $80(17,7 \%)$ \\
\hline$*$
\end{tabular}

the Internet for leisure pursuits, to search for information and to communicate with their peers.

The percentage of adolescents looking for health information on the Internet reflected in this study is within the range described in existing literature (40\%$73.4 \%)[4,11-16]$. This result is considerably remarkable since most research articles related to this topic have been conducted on adolescents who were native speakers of English and there are no articles on Spanish adolescents.

Literature on the topic reflects, similarly to this study, that there is a statistically significant difference between adolescents who browse the Internet more intensively and those who do it less frequently, the former being more likely to search for information on health matters than the latter [15-17]: Moreover, health topics most frequently searched by respondents correspond with those identified in previous studies: body image, exercise 
and fitness, diets and nutrition, sexual information and sexually transmitted diseases $[9,11,18,19]$.

This study has several limitations which should be taken into account in order to analyse the results. Firstly, although the aim of this survey was not to determine or acknowledge any gaps or shortcomings in IT training or computer literacy, the existence of these could bias the results shown. On the other hand, a cluster sample was performed, which makes it impossible to know beforehand the number of questionnaires, however, in Spain there are a limited number of students per classroom (nearly 30 ).

One significant result was that when asked which pages they used most to obtain health information all the adolescents surveyed replied that they accessed the information through Google-type search engines. It seems to show clearly that these mechanisms prevail mainly because they are easy, accessible, fast and contain a great deal of information [20]: Nevertheless, it is significant that these kind of web sites works by means of algorithms and some web pages are more likely to be among those recommended than others. This is especially important because these pages are usually sponsored by the private sector, which could influence young people [21], and because of the quality differences reported in their content [22]. Training adolescents in the correct use of the online information sources is a key element in optimizing interaction with the web [23].

\section{Conclusions}

From the point of view of public health, these results represent an opportunity for health services. Hence, it is necessary to design websites more adequate for adolescents needs that may provide them with reliable and confidential information. In this regard, literature depicts that children and teenagers tend to believe that "if you can find it online then it must be true" [24]. In conclusion, it seems plausible to claim that websites designed and managed by health services should have a predominant position among interventions specifically addressed to young people.

\section{Acknowledgements}

Project subsidised by the Ministry of Health for the Andalusian Regional Government (Exp. 134/2005).

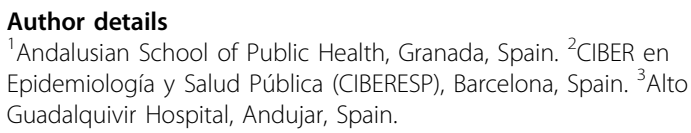

\section{Authors' contributions}

AOLL, JJP and CBT drafted the manuscript and performed the statistica analysis. JJP, MCSS and JFGG participated in the design and of the study. JJP and JFGG conceived the study, participated in its design and coordination and helped to draft the manuscript. All authors read and approved the final manuscript.

\section{Competing interests}

The authors declare that they have no competing interests.

Received: 12 May 2009

Accepted: 29 January 2010 Published: 29 January 2010

\section{References}

1. Instituto Nacional de estadística: Survey on the Equipment and Use of ICT.http://www.ine.es/, [Accessed: 2010-01-20].

2. Punamäki RL, Wallenius $M$, Nygard $C H$, Saarni L, Rimpelä A: Use of information and communication technology (ICT) and perceived health in adolescence: The role of sleeping habits and waking-time tiredness. J Adolesc 2007, 30(4):569-85.

3. Buckingham D: The electronic generation? Children and new media. Handbook of new media: Social shaping and consequences of ICTS Livingstone, London: SageLievrouw LA 2002, 7:7-89.

4. Rideout V: Generation Rx: How young people use the Internet for Health information. Kaiser Family Foundation Survey 2001 http://www.kff.org/ entmedia/loader.cfm?url=/commonspot/security/getfile.cfm\&PagelD=13719, [Accessed: 2010-01-20].

5. Kanuga M, Rosenfeld WD: Adolescent sexuality and the internet: the good, the bad, and the URL. J Pediatr Adolesc Gynecol 2004, 17:117-124.

6. Gray NJ, Klein JD, Noyce PR, Sesselberg TS, Cantrill JA: Health informationseeking behaviour in adolescence: the place of the internet. Soc Sci Med 2005, 60:1467-78.

7. Rice RE: The Internet and health communication: a framework of experiences. The Internet and Health Communication: Experiences and Expectations Thousand Oaks, Calif: Sage Publications 2001, 5-46.

8. Hesse BW, Nelson DE, Kreps GL, Croyle RT, Arora N, Rimer BK: Trust and Sources of Health Information The Impact of the Internet and Its Implications for Health Care Providers: Findings From the First Health Information National Trends Survey. Arch Intern Med 2005, 165:2618-2624.

9. Kell B: The strengths and limitations of the internet as a health information resource for adolescents. J Adolesc Health 2009, 4:520.

10. Jiménez-Pernett J, Salcedo-Sánchez MC, García-Gutiérrez JF: Necesidades y expectativas de información sobre salud en Internet para adolescentes: Una prueba piloto. Revista eSalud 2007, 3(10)http://www.revistaesalud.com, [Electronic journal]. Accessed: 2010-01-20].

11. Gould MS, Harris Munfakh JL, Lubell K, Kleinman M, Parker S: Seeking help from the Internet during adolescence. J Am Acad Child Psy 2002, 41:1182.

12. Bleakley $A$, Merzel $C R$, VanDevanter NL, Messeri P: Computer access and internet use among urban youths. Am J Public Health 2004, 94:744.

13. Gray NJ: The Internet: A window on adolescent health literacy. J Adolescent Health 2005, 37(243):e1-e7.

14. Borzekowski DL, Rickert VI: Adolescents, the Internet, and health: issues of access and content. J App Dev Psychol 2001, 22:49-59.

15. Ogan CL, Ozaka M, Groshek J: Embedding the Internet in the lives of college students. Online and Offline behaviour. Soc Sci Comput Rev 2008, 26:170-177.

16. Hufken V, Deutschmann M, Baehring T, Scherbaum W: [Use of the internet for health care information: results from a national telephone survey]. Soz Praventivmed 2004, 49(6):381-90.

17. Lenhart A, Madden M, Macgill AR, Smith A: Teens and social media. Pew Internet and American Life Project report, 2007 [online].http://www. pewinternet.org, [Accessed: 2010-01-20].

18. Skinner H, Biscope S, Poland B, Goldberg E: How adolescents use technology for health information: implications for health professionals from focus group studies. J Med Internet Res 2003, 5:e32.

19. Borzekowski DL, Fobil JN, Asante KO: Online Access by Adolescents in Accra: Ghanaian Teens' Use of the Internet for Health Information. Developmental Psychology 2006, 42:450-458.

20. Boyer C, Geissbuhler A: Health and the Internet for all. Int J Med Inform 2006, 75:1-3.

21. Miller EA, West DM: Characteristics associated with use of public and private web sites as sources of health care information. Med Care 2007, 45:245-251.

22. Babio G, Bermúdez Tamayo C, García JF, Márquez S: Selección y evaluación de sitios web dirigidos a pacientes. Andalusian Agency for Health Technology Assessment 2006http://www.hvn.es/invest_calid_docencia/ bibliotecas/publicaciones/archivos/doc_52.pdf, [Accessed: 2009-01-26]. 
23. Truccolo I, Bianchet K, Dal Maso L, Cognetti G, De Paoli P: Internet as a health education tool by Italian high school students. Journal of the

European Association for Health Information and Libraries 2009, 5http:// www.eahil.net/journal/journal_2009_vol5_n2.pdf\#page=15, [Electronic journal].

24. Bremer J: The internet and children: advantages and disadvantages. Child Adolesc Psychiatr Clin N Am 2005, 14(3):405-28, viii.

Pre-publication history

The pre-publication history for this paper can be accessed here:http://www. biomedcentral.com/1472-6947/10/6/prepub

doi:10.1186/1472-6947-10-6

Cite this article as: Jiménez-Pernett et al:: Use of the internet as a source of health information by Spanish adolescents. BMC Medical Informatics and Decision Making 2010 10:6.

Submit your next manuscript to BioMed Central and take full advantage of:

- Convenient online submission

- Thorough peer review

- No space constraints or color figure charges

- Immediate publication on acceptance

- Inclusion in PubMed, CAS, Scopus and Google Scholar

- Research which is freely available for redistribution

Submit your manuscript at www.biomedcentral.com/submit 